\title{
A multi-agent-based approach for address geocoding in poorly mapped areas through public company data
}

\author{
Mouhamad Al Mansour KEBE, Roger Marcelin FAYE and Claude LISHOU \\ LTI, Ecole Superieure Polytechnique, Universite Cheikh Anta Diop, Dakar, Senegal
}

\begin{abstract}
In this study, we present an original method that enhances geocoding systems in poorly mapped areas thanks to public company data and a multi-agent system. In contrast with industrialized countries, many developing countries lack formal postal address systems assignments and usage, making the operation of translating text-based addresses to absolute spatial coordinates, known as geocoding, a big challenge. We recreated a standard of address as it is perceived and used by local people, a kind of nonofficial national address standard since there is no official one in these areas. Then, we designed a multi-agent system in which agents are assigned different tasks of geocoding process and can perform negotiation to achieve a global objective: find the best possible match or approximation of a location-based on current knowledge. Verification of the usefulness of the proposed approach is made in comparison with Google Geocoding API which shows that the proposed approach has great potential to geocode addresses considering local context semantic issues.
\end{abstract}

Keywords: geocoding; multi-agent; text mining; knowledge discovery; address standard.

\section{INTRODUCTION}

From standard service delivery to emergency system dispatching, addresses are the most common and convenient way to locate people. Addresses are easily comprehensible to people, but not directly suitable for use in an IT environment. Translating text-based addresses to absolute spatial coordinates is known as geocoding. However geocoding technology is very common on commercial Geographical Information Systems (GIS) products, it's usually limited to fully standardized structures with respect to elements order as well as writing style.

In contrast with industrialized countries, many address systems in developing countries lack standards, making the addressing system ambiguous, incomplete or imprecise. The prompt provision of a precise location from unstructured or even vague addressing data provided by people is critically important, especially in emergency situations, and has a socio-economic impact on day-to-day life.

Furthermore, with the rapid development of ecommerce and the internet, products, and services delivery to customers is a challenge for companies, therefore increasing the need for appropriate geocoding tools in the poorly mapped area. In fact, even if an online mapping system is fairly widely used, many developing countries suffer from good addressing and geocoding system, even internet connectivity.

Due to the essential life services, they provide, water, energy, and garbage collection utility companies have mastered addressing and geocoding systems for years now. Through their day-to-day interaction with customers to quickly troubleshoot water supply breakdowns or electricity distribution failures, these utility companies need to have a good knowledge of the field they operate in. To deal with this permanent challenge, these companies have to create their own geolocation systems that have become over the years an important source of geographical and customer address data.

Hence, we investigate ten years of address data collected by Senegal power company through customer trouble calls.

On any power outage, a verbal description of their location is given by the customer to call center officers without any account references. This collected data is characterized by its vagueness and full of misspelling or unknown places from common mapping facilities.

To express these challenges, we first needed to produce an address standard by text mining historical data and creating a reference dataset before being able to achieve the matching operations.

Afterward, we designed a multi-agent system in which agents are assigned different tasks of geocoding process and can perform negotiation to achieve a global objective: find the best possible match or approximation of a location-based on current knowledge.

The rest of the paper is organized as follows: Section 2 presents the background of the study including geocoding process and literature review. In section 3, the model of 
the proposed system is set out with a definition of a standard address format from data and a description of the proposed multiagent system with its implementation. In section 4, experiments to measure the accurateness of the proposed approach are carried out in comparison to the results of Google Maps Geocoding API against a set of local addresses for which we have verified latitudelongitude and we discuss results.

\section{BACKGROUND}

\section{A. The process of geocoding and its challenge}

As well documented in the literature [1-3], within the classical approach, the geocoding process is divided into three main phases: address normalization, address matching, and address locating.

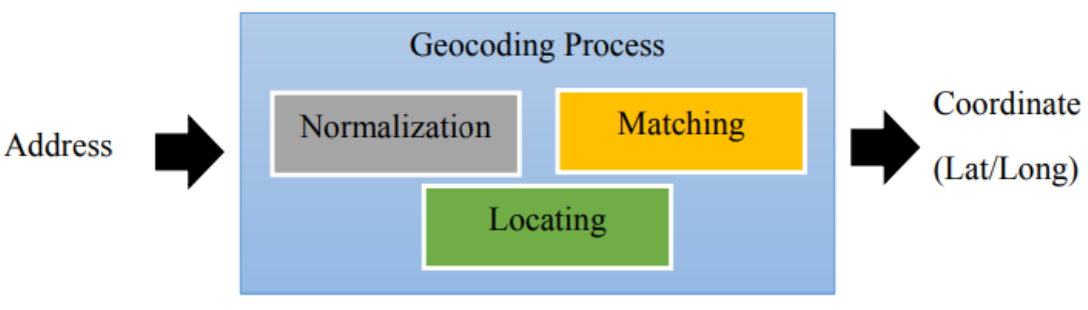

Fig. 1. the process of geocoding.

- The normalization phase transforms the address to a standardized form which allows accomplishing the comparison with reference data. Because addresses are not free from errors, they must be cleaned and standardized to get the same format as the reference data. The cleaning process involves solving issues such as case variation, abbreviation, and punctuation. Standardization is accomplished by tokenizing the address string and assigning meaning to each token from different address element types.

- The matching phase is the attempt to link the normalized address to a corresponding record from the reference data set. The performance of this stage depends on the completeness of the reference data. If exact matching cannot be obtained, the approximation is made to get the best available adjacent area in the data set.

- Locating process allow to return of a geocode, thanks to geographic coordinate assigned to a matched address in reference data. The geographic coordinate goes from polygons representing locality (which have a coordinate assigned to his centroid) through line segment representing street (coordinate assigned to his mid-point) to point representing single address.

From this brief description of the geocoding process, we can notice that we face two big challenges when attempting to geocode address in the poorly mapped area:

- Input address must be converted to a standardized format but there is no standard address in many developing countries (as reported in [4]).

- The standardized address should be compared to a reference data set but since these areas are poorly mapped, incomplete databases with unknown places are very common from all mapping facilities.

\section{B. Related work}

Geocoding is a well-studied question with plenty of contributions that have been proposed to expand the process especially in the domain of classical geocoding [1] but less in what we can call intelligent geocoding which deal with geocoding difficult address by using control and knowledge improvements $[3,5]$ to depart from simply matching and table lookups approaches. Since addressing systems vary largely between countries, as addresses have a strong cultural bias, one main part of studies revolve around some issues introduced by the natural language in the process of geocoding such as in Chinese [6-8] or Croatian [9] and more specifically on Twitter [10].

Another part of the current geocoding literature deals with geocoding application and issues solving in an explicit geographic area such as in Croatia [11], Turkish [12], Brazil [13], China [6-8], Australia [14], South Africa [15], Morocco [16], Cuba [17] and India [18]. Most of these countries are developing ones and have to deal with rapid urban growth which introduces problems such as ambiguous region boundaries and lack of convention in spellings of toponyms. Concerning developed areas, the studies deal mainly with the verification of the suitability of online geocoding tools [2] for a specific region as we can find in $[11,19,20]$ for Austria, Quebec, and Germany. Address Standard issues are also discussed in [21-23, 4,1].

This literature survey shows a strong dynamic in geocoding process from a regional and cultural point of view. Thus, to improve the geocoding course, knowledge needs to be added in the process to take into consideration the lack of standard, semantic issues, and complicated logic existing in many countries. Therefore, Multi-Agents System (MAS) which utilizes theories and concepts from 
many areas such as computer science, artificial intelligence, distributed systems, social sciences, economics, organization, and else is a good candidate for this purpose.

In this tendency, in [5] Ran Wei and al. (2009) present a knowledge-based agent prototype for Chinese address geocoding. Toward the statement that Chinese address geocoding is a difficult problem to deal with due to intrinsic complexities in Chinese address systems including Chinese language and civil history and a lack of standards in address assignments and usages, the authors propose a spatial knowledge-based agent prototype to improve existing address geocoding algorithm. To construct this agent, they first introduce a knowledge base consisting of a basic ontology for the Chinese address validation domain and an internal fact database. An inference ruleset is integrated into this agent to deduce the spatial accuracy of these potential matches. However, this approach is limited to some inferential ability to help the matching process and had to be improved to solve an issue like geocoding addresses containing two or more geographical classes of the same kind.

In [24] Matthew J. Hutchinson and Bert Veenendaal (2011) present an agent-based framework for intelligent geocoding. Having noted that despite progress in the field of geocoding, there remain a sizable proportion of addresses that are difficult to geocode due to missing information and wrong addresses, they explore how agent-based processing, which utilizes the belief, desire, intention (BDI) model, can add intelligence to the geocoding process. The goal of the system is to correct address element allowing to find them in the reference data set and every agent pursues its own intention to this goal. Nevertheless, this study is confined to geocoding matching process assuming that, it will take longer but complex sites and rural sites will have reliable geocode data.

Our work extends those of Hutchinson and al which is conducted in the context of a developed country with comprehensive geocode data updated every three months (the Australia G-NAF files). In contrast with Hutchinson, we are in a poorly mapped area [25] which conduct to include more dynamics in all geocoding process (data normalization, data set acquisition, and cleaning). From the geographical area's points of view, as far as we know, this is the first study of this kind in French-speaking West Africa area.

\section{Current situation of addressing in Senegal and use of address standard}

The addressing system, which can be defined as operation allowing to physically localize a property as a building, using maps and panel systems indicating house number and street names, is of great importance for any country $[4,26]$, in particular for the provision of services and urban management.
Demographic explosion in major developing countries has led to an uncontrolled and un-co-ordinated expansion of the residential area in cities so that more than half of streets are with no name or address, especially in the poorest neighborhoods $[27,28]$. Without a standard and formal addressing system, locating will remain a great challenge and critically important when it comes to mobilizing the first wave of emergency services, such as firefighters, police, and ambulances. So, we are in the context of a poorly mapped area.

First addressing operations in Africa go back to the beginning of the 1990s, mostly supported by French Development Aid (AFD) or the World Bank (WB). Eleven Cities of Senegal have thus been able to benefit from addressing system projects in 1999 [27].

Although as we draw our conclusions on the result, we find a limited success of this operation [29] due to noncompliance paneling of roads or lack of monitoring and poor maintenance, some great achievements can be recognized such as subdivision of addressing zones and street codification with the SYSCOL system (Système de Codification des Localités - Cities's Codification System).

Given formalism and standardization of address in Senegal, several milestones have been achieved recently. In 2012, the Government of Senegal created the NICAD Cadastral Identification Number (Decree 2012 - 396 of March 27, 2012), a unified identification number of 16 characters whose main objective is to solve problems of proprieties and lands governance. The NICAD is created from the SYSCOL with an addition of a section number and a house number.

The postal code, which is a recommendation of the Universal Postal Union for the standardization of addresses, was introduced in Senegal in 2015 [30]. It is a 5-digit coding model for the various postal establishments.

The arrival of Google Street View in Senegal [31] in early February 2017, the first French-speaking West Africa country to benefit from this technology, promises to be a revolution in the area of addressing with a possibility to walk virtually in the Capital town Dakar and in the major cities of the country. This survey points out that addressing the system is a big challenge for developing countries such as Senegal. In this kind of situation, utilities could not help but implement their own different addressing systems. However, the collected information is associated with a formally identifiable property with an administrative document.

Moreover, when the customer calls to report a power outage in Senelec, Senegal public energy utility, he gives his exact living address and a description of points of interest (POI) allowing him to find him easily since any power connectivity database does not exist. This way made it possible to collect indirectly over the years' data containing the point of interest, facilities, or home of well- 
known personalities which constitutes suddenly a huge source of urban data too often non-existent.

Through this "collective memory," we recreate a standard of address as it is perceived and used by people that we have called the ontology of urban geography in Senegal, a kind of non-official national address standard.

\section{PROPOSED APPROACH}

\section{A. Definition of an address standard}

To define an address standard, an ontology for this domain is constructed as the basic vocabulary to represent spatial knowledge in the address geocoding domain. Hence, we analyzed ten years of address data collected by Senegal public energy utility through customer trouble calls. This collected data is characterized by its sketchiness and full of misspelling and unknown places from common online mapping. This basic ontology includes geographical classes such as city, county, road, house number, community, building number, points of interest (POI), and other concepts needed for comparing and evaluating address matches.

Example of address data from the trouble call data corpus:

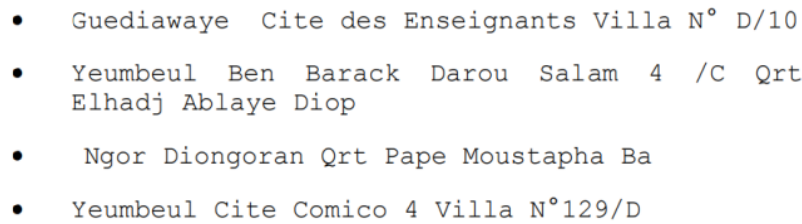

Thanks to the determination of the most often used terms we have identified the terminology used to describe an address.

Words like "villa" (house), "qrt" (abbreviation of French word quartier which mean neighbourhood), 'rue' (street) are in focus.

Many mistakes and spellings are encountered in the data due to typos and abbreviations knowing that they are collected verbally by phone from call center. We give the example of the spelling of a locality called Baghdad in the suburbs of Dakar - named after the capital of Iraq (34 different spellings were identified): bagdada, bagdade, bagda, bagdadd, bagdad, bagdah, badagg, bagdag, bagbad, badgad, bagdadv, bagad, bagadad, baggdad, bagddad, baghdad, badag, bagadd, bahdagg, bakhdag, badgdad, bgdad, bagdade, badgad, bagadad, bagdad, bagdada, bagddad, bagdadv, bagadd, bgdad, bagdadd, badgdad, baggdad.

For the common word, 'baobab' (a neighborhood in Dakar named after an emblematic tree) we found 24 different spelling: baboab, baoba, baoabab, baoobab, boaobab, baobas, baoababs, baoubab, baobao, baboba, baobabs, baobab, boabab, baobaps, boababs, bobab, baobob, babao, babobab, baba, baoabs, baobap, babaob, baobaob,

In order to reunite the various spelling of frequent words, language processing algorithms have been used such as Levenshtein distance and Jaro-Winkler distance combined with TF-IDF (Term Frequency-Inverse Document Frequency) [38].

This allows isolating the words in table 1.

TABLE I. LIST OF MOST FREQUENT ENTITY

\begin{tabular}{|l|l|l|l|l|l|}
\hline rank & entity & rang & entity & rank & entity \\
\hline $\mathbf{1}$ & allée & $\mathbf{1 1}$ & ilot & $\mathbf{2 1}$ & rondpoint \\
\hline $\mathbf{2}$ & angle & $\mathbf{1 2}$ & immeuble & $\mathbf{2 2}$ & route \\
\hline $\mathbf{3}$ & appartement & $\mathbf{1 3}$ & km & $\mathbf{2 3}$ & rue \\
\hline $\mathbf{4}$ & avenue & $\mathbf{1 4}$ & lot & $\mathbf{2 4}$ & unité \\
\hline $\mathbf{5}$ & bâtiment & $\mathbf{1 5}$ & lotissement & $\mathbf{2 5}$ & université \\
\hline $\mathbf{6}$ & bloc & $\mathbf{1 6}$ & magasin & $\mathbf{2 6}$ & villa \\
\hline $\mathbf{7}$ & boulevard & $\mathbf{1 7}$ & marché & $\mathbf{2 7}$ & village \\
\hline $\mathbf{8}$ & cantine & $\mathbf{1 8}$ & parcelle & $\mathbf{2 8}$ & voie \\
\hline $\mathbf{9}$ & cité & $\mathbf{1 9}$ & quartier & $\mathbf{2 9}$ & zone \\
\hline $\mathbf{1 0}$ & etage & $\mathbf{2 0}$ & rdc & $\mathbf{3 0}$ & croisement \\
\hline
\end{tabular}

We classify these address concepts in family and settle a hierarchy between them. Considering the current national administrative division of the country including Administrative district and Municipality we get figure 3 with the main families in focus: property, subdivision, administrative division, space for circulation, municipality, and administrative district.

The developed version of the addressing concept is presented in figure 4 with detail of words used frequently in each family of concepts giving an ontology of how address is nowadays expressed by Senegalese People. This ontology is an input used by the multi-agent system to accomplish the goal of the LOGEMAS system.

\section{B. LOGEMAS - Location Geocoding with Multi-Agent} System

In this section, we present the LoGeMAS (Location Geocoding with Multi-Agent System) architecture in which the various geocoding tasks are delegated to different agents.

\section{1) Multi-agent Architecture}

To achieve the task of geocoding, agents are assigned different tasks of geocoding process and can perform negotiation through FIPA protocol to achieve the global objective: text mining and pattern recognition to find the best possible match or approximation of a location-based on current knowledge.

Figure 5 depicts the interaction in the model composed of five types of agents. 


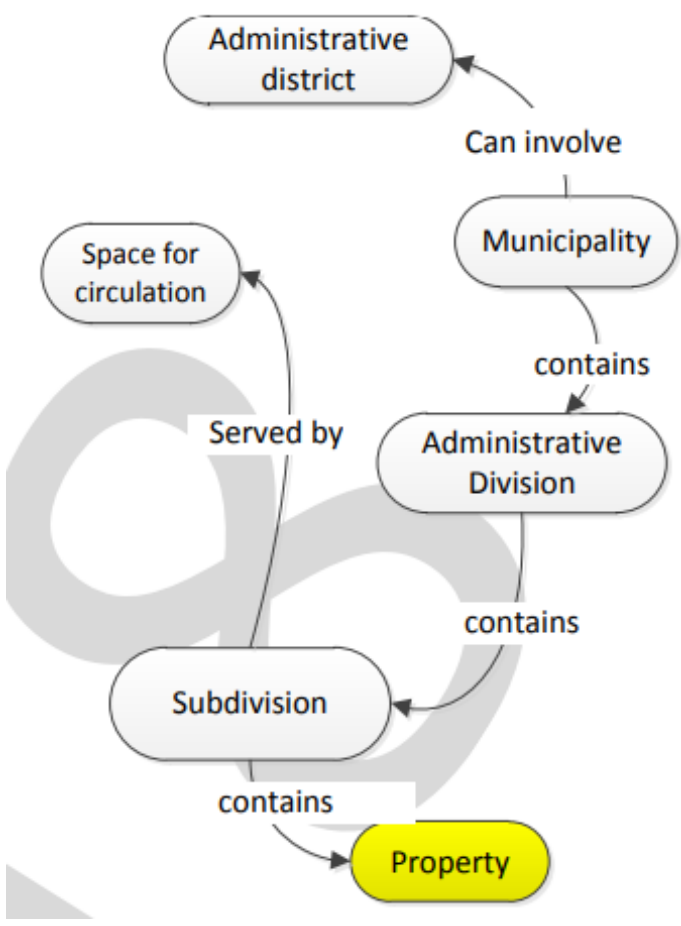

Fig. 2. simplified addressing concept hierarchy.

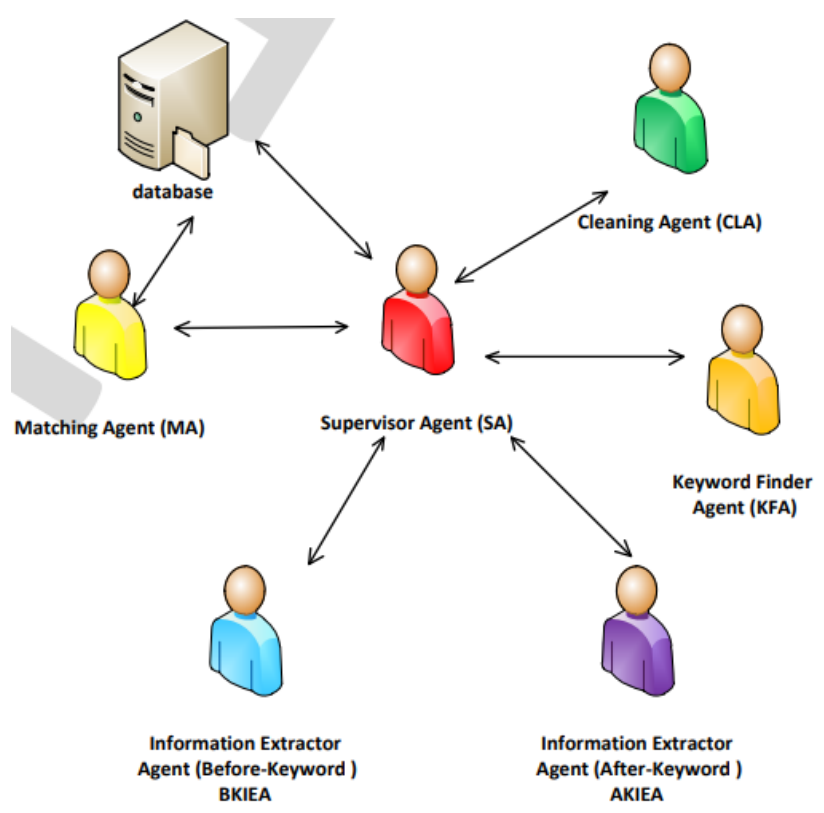

Fig. 3. Multi-Agent LOGEMAS model.
- Supervisor Agent (SA): his role is to manage the different processes through a well-defined sequence of events. As a coordinator agent, SA dispatches the different tasks to other agents.

- Cleaning Agent (CLA): his role is to clean the provided address, as in the normalization phase in the geocoding process (see section 2.) The algorithm used by CLA includes transforming text to lower case and deleting all special characters.

- Keyword Finder Agent (KFA): his objective is to find the different entities of the ontology, called a keyword, present in the provided address and to classify them as described by the knowledge provided by ontology (see fig 4 ).

- Before Keyword Information Extractor Agent (BKIEA): as his name shows, this is an information extractor agent specialized in information appearing before a keyword. Example in the address: "Guediawaye Cite des Enseignants Villa $\mathrm{N}^{\circ} \mathrm{D} / 10 "$ BKIEA will retrieve the couple ['Guediawaye', 'des Enseignants']

- After Keyword Information Extractor Agent (AKIEA): as his name show, this is an information extractor agent specialized in information appearing after a keyword. Example in the address: "Guediawaye Cite des Enseignants Villa $N^{\circ} \mathrm{D} / 10^{\prime}$ AKIEA will retrieve the couple ['des Enseignants', ' $\left.\mathrm{N}^{\circ} \mathrm{D} / 10^{\prime}\right]$

- Matching Agent (MA): The Matching Agent's role is to do the matching action by finding geocode corresponding to address as described in geocoding process in section 2. From each found keyword completed with his proprieties, information is looked at in the database and the process is completed with the following heuristics rules that allow defining the accuracy:

Rule 1: For all kinds of keywords, their determinant (own name of the keyword) is always after the keyword excepted for those of space for circulation family [rue, angle] and [ étage] (upstairs).

E.g.: for address "Guediawaye Cite des Enseignants Villa $\mathrm{N}^{\circ} \mathrm{D} / 10^{\text {" }}$ "des Enseignants" is the name of keyword 'cite'

" $n^{\circ} \mathrm{D} / 10^{\prime}$ " is the name of the keyword 'villa' 


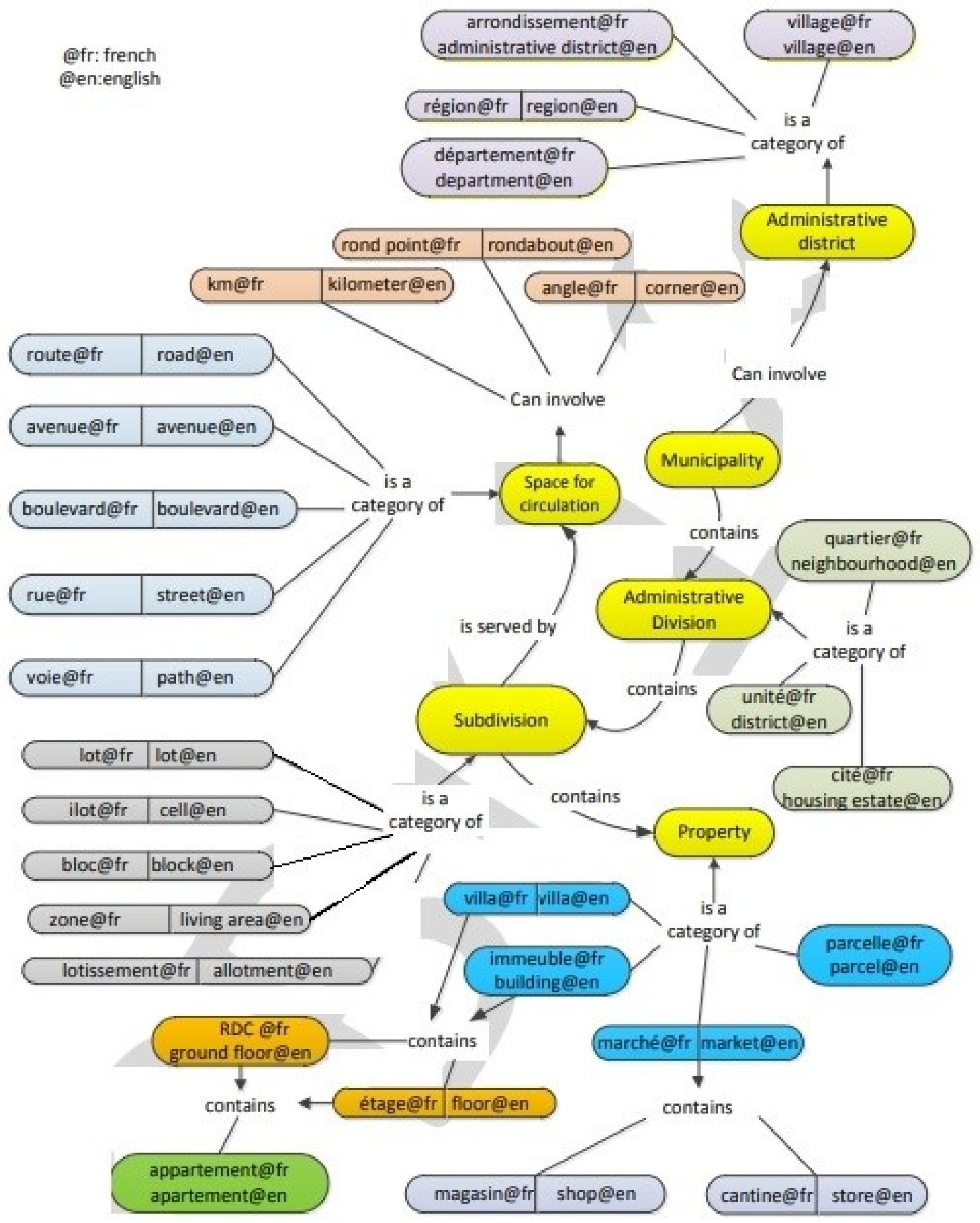

Fig. 4. ontology of urban geography in Senegal. 
Rule 2: if the address doesn't begin with a keyword the first before keyword text is to be found on the elder family of the first appearing keyword.

E.g.: for address "Guediawaye Cite des Enseignants Villa N ${ }^{\circ} \mathrm{D} / 10^{\text {" which }}$ does not begins with keyword. Guediawaye is to find in the elder families of "cite" (belonging to 'Administrative division') which can be 'municipality' or 'Administrative district'

Rule 3: if the keyword is not found, the matching is to be fetched first in the POI table.

\section{Data set acquisition}

To track crew performance during outage recovery, Senelec utility has introduced a vehicle tracking system in 2015. The data collected during breakdown reparation combined with these captured tracking data gives a potential of learning new regions and landmarks by reverse geocoding concerned customer addresses.

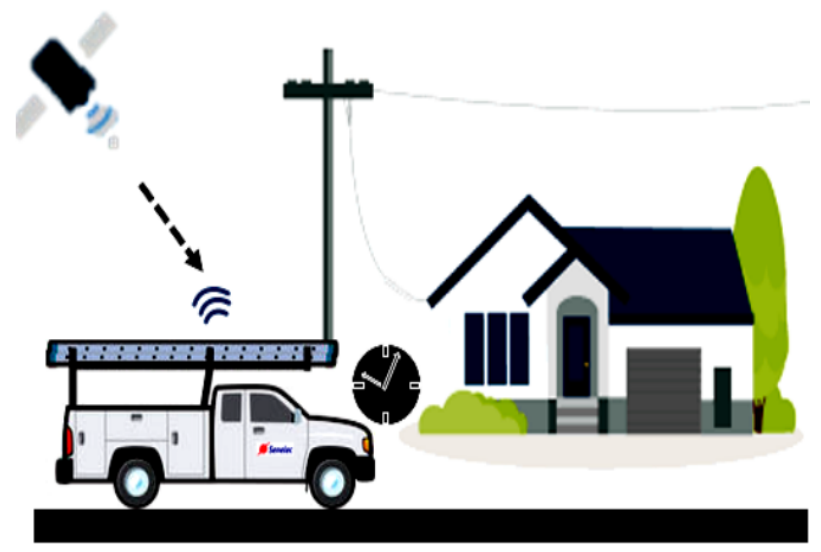

Fig. 5. use of crew vehicle tracking data to create reference dataset.

\section{The Multi-Agent System design and implementation}

To implement a multi-agent system, there are several open-source agent platforms available in the literature that helps developers to build a complex agent system in a simplified manner. The GAMA platform [33, 34] was chosen to implement our system. This platform is a new trend in multi-agent development enables multi-agent development through an intuitive interface and programing language GAML. GAMA has the advantage to implement many features like FIPA compliance, Geographical Information System (SIG), and the ability to build spatially explicit multi-agent simulation which is one characteristic of the geocoding system.

\section{EXPERIMENT RESULT AND DISCUSSION}

To challenge our approach and demonstrate its capability, a case study in Dakar City Senegal is carried out with text mining and pattern recognition. First, we measure the ability of the system to geocode up to different levels of precision from the proposed address standard including property, subdivision, administrative division, space for circulation, municipality, and administrative district. To achieve this test, we run the LOGEMAS process through one month of trouble call data containing 6321 addresses (June 2015 data). The test is compliant since only 23 addresses were not recognized. Figure 9 shows an example of the results provided by LOGEMAS system.

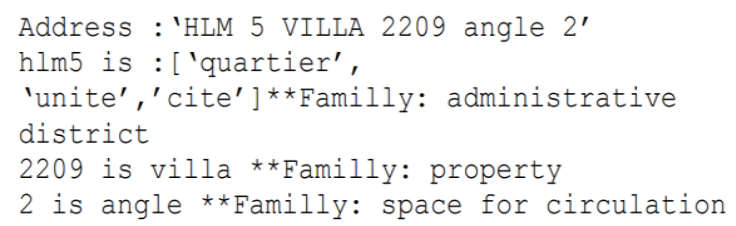

Fig. 6. Sample of address recognition through LOGEMAS process.

When analyzing the address that was not well recognized we found that they had in common the fact of containing natural language part of speech like in 'Yarakh Hann Pecheur ne connait pas le nom du Chef de qrt' (meaning Yarakh Hann Pecheur doesn't know the name of the head of district!!!) .

Finally, a comparison of LOGEMAS results with those of Google's geocoding service against a set of addresses verified latitude-longitude coordinates were conducted and we arrive at these conclusions:

- Google Maps was not able to consider semantic issues while LOGEMAS well recognized the standard address as expressed by local people.

- Google geocoding service is limited to the street name, municipality, and completed Point of Interest (POI) and LOGEMAS tries to give a level of precision from its known database.

We can conclude that the architecture we are developing has great potential to geocode addresses considering local context issues with the integration of semantic questions.

\begin{tabular}{|c|c|c|c|}
\hline & A & $B$ & U \\
\hline 1 & ADRESSE & $=$ Lat & - Lng \\
\hline 2 & 63 AVENUE LAMINE GUEYE & 14,6710559 & 9 \\
\hline 3 & sud foire villa n 13 & 14,7276771 & $-17,5015105$ \\
\hline 4 & YOFF NDEUGAGNE ne connait pas le nom du chef de grt & ZERO_RESULTS & ZERO_RESULTS \\
\hline 5 & YOFF TONGHOR QRT BAMAR NDIAYE & ZERO_RESULTS & ZERO_RESULTS \\
\hline 6 & SACRE COEUR 2 VILLA N $8597 A$ & 44,8497701 & $-0,6045212$ \\
\hline 7 & HANN MARISTE 2 VILLA N0Z 95 & ZERO_RESULTS & ZERO_RESULTS \\
\hline 8 & PATTE D OIE BUILDERS VILLA N*E/18 BIS & 14,7588927 & $=17,4705514$ \\
\hline 9 & GUEDIAWAYE & 14,7753661 & $-17,3996674$ \\
\hline 10 & GUEDIAWAYE HAMO 4 VILLA N ${ }^{\circ}$ S/66 & ZERO_RESULTS & ZERO_RESULTS \\
\hline 11 & CAMBERENE 1 MBANE QRT MOUSTAPHA MBENGUE & ZERO_RESULTS & ZERO_RESULTS \\
\hline 12 & YOFF NDENATT QRT ISSA KEBE & ZERO_RESULTS & ZERO_RESULTS \\
\hline 13 & YEUMBEUL NORD CITE COMICO 4 VILLA N* C 267 & ZERO_RESULTS & ZERO_RESULTS \\
\hline 14 & PAU 12 & 8,3685721 & $1 \quad-82,5402737$ \\
\hline 15 & AVENUE LAMINE GUEYE RUE TOLL DIAZ X BALET & ZERO_RESULTS & ZERO_RESULTS \\
\hline 16 & 11 RUE JEAN JAURES & 48,8894678 & 2,2906427 \\
\hline
\end{tabular}

Fig. 7. sample of Google Maps Api showing unknown addresses. 


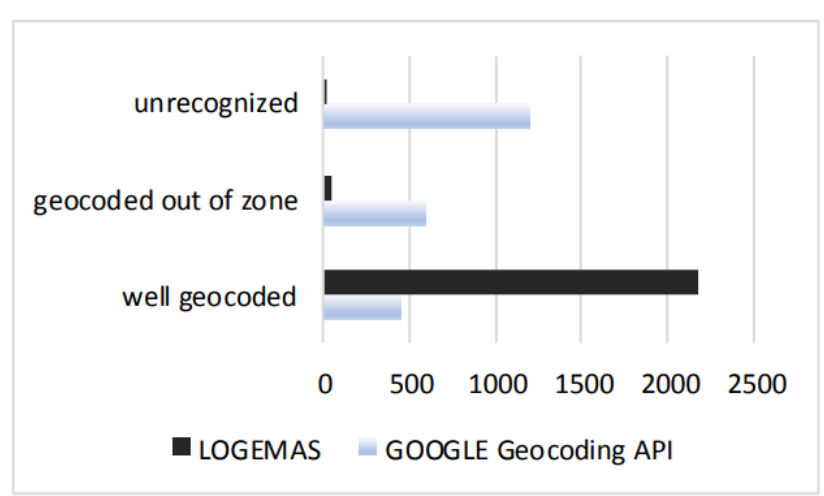

Fig. 8. Comparison between LOGEMAS and Google Maps Api geocoding process results.

\section{CONCLUSION AND FUTURE WORK}

In this paper, we presented a system called LOGEMAS - Location Geocoding with Multi-Agent System. We investigated ten years of address data collected by Senegal public energy utility through customer trouble calls. We recreated a standard of address as it is perceived and used by people, a kind of nonofficial national address standard. Afterward, we designed a multi-agent system in which agents are assigned different tasks of geocoding process and can perform negotiation to achieve a global objective: find the best possible match or approximation of a location-based on current knowledge. Verification of the usefulness of the proposed approach is made in comparison with Google Geocoding API which shows that the proposed approach has great potential to geocode addresses considering local context semantic issues. In future work, the tool will be enhanced with more semantic skills and propose an application to outage management, a way of giving something back to power utilities.

\section{REFERENCES}

[1] D.W. Goldberg, A geocoding best practices guide (North American Association of Central Cancer Registries, 2008)

[2] H.A. Karimi, M.H. Sharker, D. Roongpiboonsopit, Geocoding recommender: an algorithm to recommend optimal online geocoding services for applications, Transactions in GIS 15(6), 869 (2011)

[3] M.J. Hutchinson, Developing an agent-based framework for intelligent geocoding (Curtin University of Technology., 2010)

[4] S. Coetzee, A.K. Cooper, M. Lind, M.M. Wells, S.W. Yurman, E. Wells, N. Griths, M.J. Nicholson, Towards an international address standard,(10th International Conference for Spatial Data Infrastructure, 2008)

[5] R. Wei, X. Zhang, L. Ding, H. Ma, Q. Li, in Geoinformatics 2008 and Joint Conference on GIS and Built environment: Advanced Spatial Data Models and Analyses (International Society for Optics and Photonics, 2009), pp. 71,461D \{71,461D

[6] Q. Tian, F. Ren, T. Hu, J. Liu, R. Li, Q. Du, Using an Optimized Chinese Address Matching Method to Develop a Geocoding Service: A Case Study of Shenzhen , ISPRS International Journal of GeoInformation 5(5), 65 (2016)
[7] D. Gao, Q. Li, in Geoinformatics 2007 (International Society for Optics and Photonics, 2007), pp. 67,530U $\{67,530 \mathrm{U}$

[8] L. Fang, Z.y. Yu, X. Zhao, in Geoscience and Remote Sensing Symposium (IGARSS), 2010 IEEE International (Ieee, 2010), pp. $3987\{3990$

[9] I. Ugrina, M. Zigo, in Central European Conference on Information and Intelligent Systems (Faculty of Organization and Informatics Varazdin, 2014), p. 276

[10] W. Zhang, J. Gelernter, Journal of Spatial Information Science 2014(9), 37 (2014)

[11] V. Cetl, T. Kliment, T. Jogun, Survey Review pp. $1\{10$ (2016)

[12] V. Yildirim, T. Yomralioglu, R. Nisanci, H. Inan, Proceedings of the Institution of Civil Engineers 167(2), 99 (2014)

[13] C.A. Davis Jr, R.O. de Alencar, Transactions in GIS 15(6), 851 (2011)

[14] P. Christen, T. Churches, A. Willmore, et al., in Proceedings of the 3rd Australasian Data Mining Conference, Cairns (2004)

[15] S. Coetzee, A.K. Cooper, South African Journal of Science 103(11-12), 449 (2007)

[16] M.E.I. Malaainine, H. Rhinane, L. Baidder, H. Lechgar, Journal of Geographic Information System (2013)

[17] C.J. de Armas Garcia, A.A.C. Gutierrez, URISA Journal 25(1), 53 (2013)

[18] A. Chatterjee, J. Anjaria, S. Roy, A. Ganguli, K. Seal, Sagel: smart address geocoding engine for supply-chain logistics, in Proceedings of the 24th ACM SIGSPATIAL International Conference on Advances in Geographic Information Systems (ACM, 2016), p. 42

[19] S. Burns, L. Miranda-Moreno, J. Stipancic, N. Saunier, K. Ismail, Transportation Research Record: Journal of the Transportation Research Board (2460), 39 (2014)

[20] D. Ahlers, S. Boll, Geoinformatik 2009 (2009)

[21] C.A. Davis, F.T. Fonseca, Geoinformatica 11(1), 103 (2007)

[22] F. Karimipour, N. Alinaghi, P. Weiser, A.U. Frank, Cognitive engineering for spatial in-formation processes: From user interfaces to model-driven design (2015)

[23] S. Coetzee, M. Rademeyer, in proceedings International Cartography Conference (2009), pp. $15\{21$

[24] M.J. Hutchinson, B. Veenendaal, Applied Geomatics 5(1), 33 (2013)

[25] M. Irwin. Mapping missing maps. [Online; accessed 20-January2017] (2014). https://www.mapbox.com/blog/mapping-missing:maps/

[26] O. Dembele, J. Yango. ladressage : un outil la mobilisation des ressources financiers locales. [Online; accessed 20-January-2017] (2009).

http://www.cifalouaga.org/Douala/Exposes/Module3/Adressageen AfriqueDembeleetTan go.pdf

[27] C. Farvacque-Vitkovic, L. Godin, H. Leroux, F. Verdet, R. Chavez, Adressage et gestion des villes (World Bank, 2005)

[28] RFI. Rue sans nom ! ladressage dans les villes africaines : indispensable, mais comment ? [Online; accessed 20-January2017] (2016). http://www.rfi.fr/emission/20160901-rue-pas-nomadressage-villesafricaines-indispensable-mais-comment

[29] S. Rouhana, D.N. Ranarifidy, V. Chomentowski. Stratgie globale d'amlioration des recettes de la ville de dakar, synthse de la dmarche septembre 2013 juillet 2014. [Online; accessed 20January-2017] (2015). https://ppiaf.org/documents/3164/download

[30] O. Fdior. lancement du code postal : la poste sarme contre la concurrence. [On-line; accessed 20-January-2017] (2015). http://www.reussirbusiness.com/actualites/lancement-du-codepostal-laposte-sarme-contre-la-concurrence

[31] A. Fontaine. Google street view desormais lance au senegal. [Online; accessed 20-January-2017] (2017). 
http://www.rfi.fr/afrique/20170217- google-street-desormaislance-senegal-dakar

[32] S.A. Graham, String searching algorithms (World Scientific Publishing Co. Pte. Ltd, 1994)
[33] K. Kravari, N. Bassiliades, Journal of Artificial Societies and Social Simulation 18(1), 11 (2015)

[34] Documentation sur la plateforme gama. "[Online; accessed 4December2016]" (2016). https://github.com/gamaplatform/gama/wiki 